\title{
Administration of a Synbiotic to Free-Living Elderly and Evaluation of Serum Cytokines. A Pilot Study
}

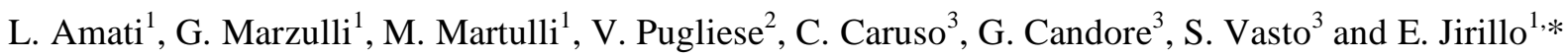 \\ ${ }^{1}$ National Institute of Gastroenterology, Castellana Grotte, Bari, Italy; ${ }^{2}$ Geriatric Center “Mamma Rosa”, Turi, Italy; ${ }^{3}$ Department \\ of Pathobiology and Biomedical Methodologies, University of Palermo, Palermo Italy
}

\begin{abstract}
Ten free-living elderly were administered with a synbiotic [fermented milk containing Lactobacillus rhamnosus Gorbach and Goldin (LGG®)] and oligofructose as a prebiotic for one month. Serum cytokines were evaluated before $\left(\mathrm{T}_{0}\right)$ and after $\left(\mathrm{T}_{1}\right)$ synbiotic administration. At $\mathrm{T}_{0}$, values of Interleukin (IL)-12, IL-6, IL-10, IL-1 $\beta$ and Tumor Necrosis Factor (TNF)- $\alpha$ were lower than normal controls, with the exception of IL-8, thus confirming previous results on the impairment of both innate and adaptive responses in elderly. At $T_{1}$, the synbiotic was able to significantly increase, depressed values of IL-1 $\beta$, IL- 6 and IL- 8 with a trend to a modest increase for the restant cytokines.

In conclusion, the synbiotic used in this study seems to be very beneficial to elderly for its capacity to maintain the immune homeostasis, even if an increase in dosage and prolongation of administration time are required for a better modulation of the aged adaptive immune response.
\end{abstract}

Keywords: Cytokines, immunosenescence, Lactobacillus rhamnosus Gorbach and Goldin (LGG®), oligofructose, probiotics, synbiotics, elderly.

\section{INTRODUCTION}

Probiotics and, in particular, lactobacilli and bifidobacteria have been shown to exert beneficial effects when administered to humans [1]. Once ingested, they reach the ileum and compete with pathogens for nutrients, also rendering the intestinal habitat hostile for microbes via their metabolites such as short chain fatty acids (SCFA) [1].

Nowadays, clinical studies with probiotics are numerous and many evidences support their beneficial role in respiratory infections [2], diarrhea [3,4], inflammatory bowel disease [5-8] and allergy $[9,10,11-13]$

Special attention has been devoted to elderly in terms of therapy with probiotics. In fact, aged people undergo a progressive decline of immune functions and, therefore, they are more susceptible to infections [14]. In this framework, there are evidences on the ability of probiotics to shorten the duration of winter infections in elderly and of respiratory infections $[15,16]$.

Even if many studies have been conducted on the effects of probiotics on the immune system, the mechanisms by which they modulate immune responsiveness are still under study.

According to Shida and Nanno [17], three main pathways of probiotic-mediated immune modulation can be hypothesized:

- $\quad$ M cells within Peyer's patches (PP) take up probiotics via transcytosis and present them to antigen presenting cells (APCs), such as macrophages (MØ) and dendritic cells (DCs) placed immediately below the intestinal epithelium;

- DCs in the intestinal lamina propria project their ramifications between intestinal epithelial cells (IECs),thus engulfing and processing probiotics;

- Probiotics interact with IECs which, in turn, activate MØ, DCs, $T$ and $\mathrm{B}$ cells in the context of PP via release of cytokines [e.g., T helper (h)-1 induction was promoted by IL12 from APC stimulated by lactobacilli].

*Address correspondence to this author at National Institute of Gastroenterology, via Turi 27, 70013 Castellana Grotte (BA), Italy; E-mail: jirillo@midim.uniba.it
$\mathrm{T}$ regulatory (Treg) cells seem to play a paramount role in the regulation of immune response after dietary administration of probiotics. In this respect, evidence has been provided that probiotics favor the conversion of immature DCs to regulatory DCs, thus leading to the induction of IL-10 producing Treg cells $[18,19]$. In this direction, another important target of therapy with probiotics is represented by IL-17 producing Th cells (Th 17 cells), which are involved in the pathogenesis of autoimmune and chronic inflammatory diseases [20]. In fact, Th1 and Treg cells induction by probiotics could inhibit Th17 activity, thus leading to an improvement of clinical manifestations in the course of autoimmune and inflammatory pathologies.

In terms of dietary compounds endowed with beneficial effects, prebiotics represent non digestible food constituents able to promote growth and activity of probiotics in the intestine [17]. At the same time, there is evidence that consumption of highly fermentable dietary fibers leads to modulation of both intestinal immune system and flora via production of SCFA. In particular, propionate and butyrate as SCFA maintain the health of gut epithelium, thus reducing the risk of inflammatory and neoplastic development in the bowel [21].

Synbiotics are a mixture of probiotics and prebiotics able to potentiate each other, thus increasing the activity of the single components. For instance, Bifidobacterium lactis HNO19 combined with the prebiotic galactooligosaccharide could increase lactobacilli and bifidobacteria in feces more than the probiotic and the prebiotic did as single components [22]. Moreover, Kanamori and associates [23] reported that a synbiotic (B. breve, Lactobacillus casei Shirota and galactoligoosaccharide) ameliorated the clinical manifestations in short bowel patients in terms of weight gain. On the other hand, clinical trials in elderly with prebiotics alone gave rise to conflicting results such as reduction of phagocytic activity and IL-6 mRNA expression [24] and no effect on the vaccination with viral and bacterial antigens [25].

Based on these last concepts, aim of this study was to evaluate the administration of a synbiotic (fermented milk containing Lactobacillus rhamnosus and the soluble fibers oligofructose) to free-living elderly. Serum cytokine modifications following synbiotic administration were recorded. 


\section{SUBJECTS AND METHODS}

Ten free-living aged people (age range 69-96) were recruited from the Geriatric Center "Mamma Rosa", Turi (Italy).

An informed consent was obtained from all participants to the study.

Aged subjects were selected according to the following criteria:

- Absence of major diseases (metabolic, cardiovascular, autoimmune and neoplastic pathologies) affecting the immune system;

- No treatment with drugs affecting the immune system at the moment and during the clinical trial;

- No viral respiratory diseases at the moment of the trial (e.g., winter infections).

\section{Dietary Regimen}

A commercial synbiotic (YOMO ABC PLUS; Milan, Italy) composed by fermented cow milk enriched with L. rhamnosus Gorbach and Goldin $\left(\mathrm{LGG}^{\circledR}\right)\left(10^{7}\right.$ bacteria/90g bottle $)$ and the soluble fibers oligofructose was administered twice a day before lunch and dinner, respectively, for one month.

\section{Blood Sampling}

Peripheral blood was taken immediately before $\left(\mathrm{T}_{0}\right)$ and after $\left(\mathrm{T}_{1}\right)$ the synbiotic administration and serum was stored at $-80^{\circ} \mathrm{C}$ until use.

\section{Normal Donors}

Ten healthy blood donor sera were collected and stored at $80^{\circ} \mathrm{C}$.

\section{Cytokine Assay}

Determination of cytokines was run using the multiplexing assay in cytofluorometry: Cytometric Bead Array (CBA) (Beckton Dickinson Biosciences, San Jose, CA, USA). In particular "CBA Human Inflammation kit" was selected to assay Interleukin (IL)-12, Tumor Necrosis Factor $\alpha$ (TNF)- $\alpha$, IL-10, IL-6, IL-1 $\beta$. and IL-8. The test CBA allows the determination of six different cytokines simultaneously in the same sample of serum. Six bead populations with distinct fluorescence intensities were coated with capture antibodies specific for IL-8, IL-1 $\beta$, IL-6, IL-10, TNF- $\alpha$, and IL12 p70 proteins. The amount of cytokines linked to beads was determined later through incubation with a mixture of antibodies conjugated with Phycoerythrin (PE) against the same cytokines but without competing with the bead's antibodies for the same site.

Ten $\mu 1 /$ test of each bead suspension were mixed and washed by centrifugation. After, mixed beads were resuspended in an appropriate buffer, incubated for $30 \mathrm{~min}$ at room temperature (RT) and protected from light. Fifty $\mu 1$ of mixed beads were transferred to each assay tube. Lyophilized standards of human cytokines were reconstituted in the appropriate diluent and incubated for $15 \mathrm{~min}$ and, then, diluted by serial dilutions using the appropriate diluent. Standard dilutions and samples were added to the appropriate sample tubes $(50 \mu \mathrm{l} /$ tube $)$.

The beads and the cytokines, in standard or in serum, were incubated for $1.5 \mathrm{~h}$ at RT protected from light. After, samples were washed with $1 \mathrm{ml}$ of wash buffer, centrifuged and added with PEdetection Antibodies $(50 \mu \mathrm{l} /$ test $)$. So, the beads linked to cytokines, in standard or in serum and the PE-conjugated anti-human cytokines were incubated for $1.5 \mathrm{~h}$ at RT protected from light and they formed a ternary complex (bead-Antibodies-Cytokine-Antibodies). After, samples were washed with $1 \mathrm{ml}$ of Wash Buffer, centrifuged and $300 \mu \mathrm{l}$ of Wash Buffer were added to each assay tube to analyze samples.

Flow cytometer "FACSCalibur" (Becton Dickinson), "Cell Quest Software" program and "CBA Analysis Software" were used.

\section{Statistical Evaluation}

Data were analyzed using Graphpad Prism (ver. 5.00) (Graphpad software inc.-San Diego, CA; USA). Data were expressed as medians, 25/75 percentiles, and range. Statistical analysis was performed with the Kruskal-Wallis test which was used to evaluate differences between paired groups. A $p$ value $<0.05$ was considered significant.

\section{RESULTS}

A drop-out of three subjects was recorded during the study because of the occurrence of pathologies not related to the dietary regimen.

No side effects were recorded in the individuals who terminated the trial.

As indicated in Fig. (1), baseline levels of IL-12 were below normal ranges even if a modest trend toward an increase was noted at $\mathrm{T}_{1}$.

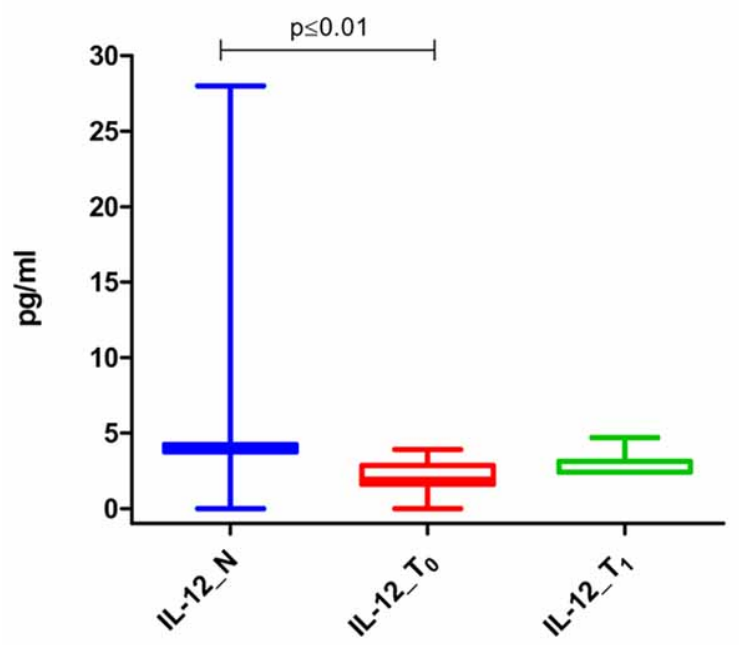

Fig. (1). Serum levels of IL-12 before $\left(T_{0}\right)$ and after $\left(T_{1}\right)$ synbiotic administration. The cytometric bead array (CBA) test was used for cytokine determination. $\mathrm{N}=10$ normal donors.

TNF- $\alpha$ levels are expressed in Fig. (2), and also in this case a trend toward an increase was evident at $T_{1}$ but values were still below normality.

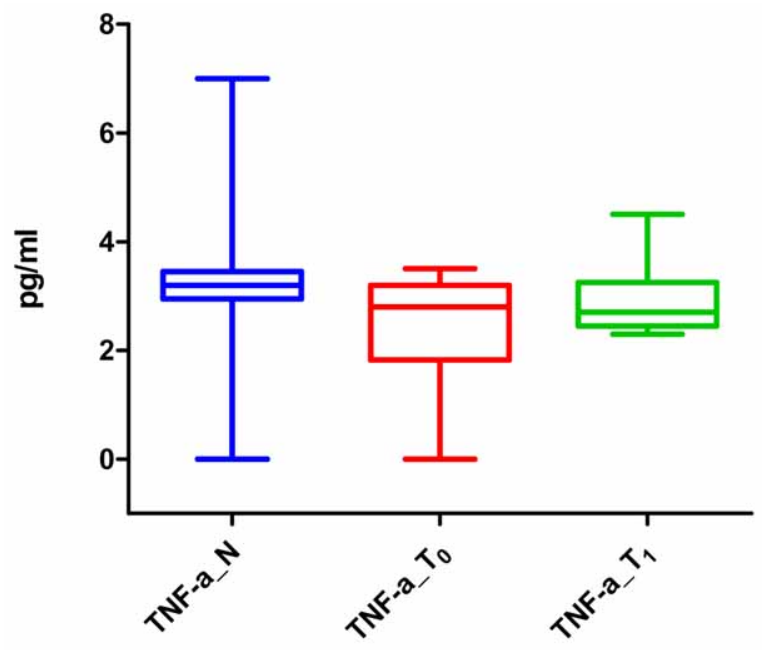

Fig. (2). Serum levels of TNF- $\alpha$ before $\left(T_{0}\right)$ and after $\left(T_{1}\right)$ synbiotic administration. The cytometric bead array (CBA) test was used for cytokine determination. $\mathrm{N}=10$ normal donors. 
Sera amounts of IL-1 $\beta$ are illustrated in Fig. (3). At To, they are still below normality $(\mathrm{p} \leq 0.001)$ and, despite a significant increase $(\mathrm{p} \leq 0.05)$ at $\mathrm{T}_{1}$, they were still lower than controls.

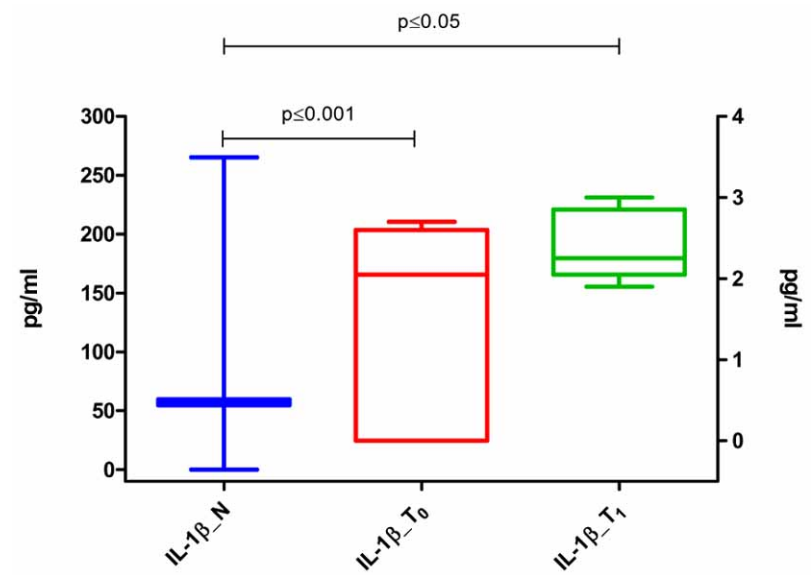

Fig. (3). Serum levels of IL-1 $\beta$ before $\left(T_{0}\right)$ and after $\left(T_{1}\right)$ synbiotic administration. The cytometric bead array (CBA) test was used for cytokine determination. $\mathrm{N}=10$ normal donors.

Levels of IL-6 [see Fig. (4)] were higher than controls $(\mathrm{p} \leq 0.01)$ and synbiotic administration tended to further increase its amounts.

Baseline values of IL-8 Fig. (5) were higher than controls ( $p$ $<0.001)$, and, at $\mathrm{T}_{1}$, they significantly $(\mathrm{p}<0.001)$ increased.

Levels of IL-10 [see Fig. (6)] were lower than controls and, despite a slight increase of values at $T_{1}$, normality was not attained.

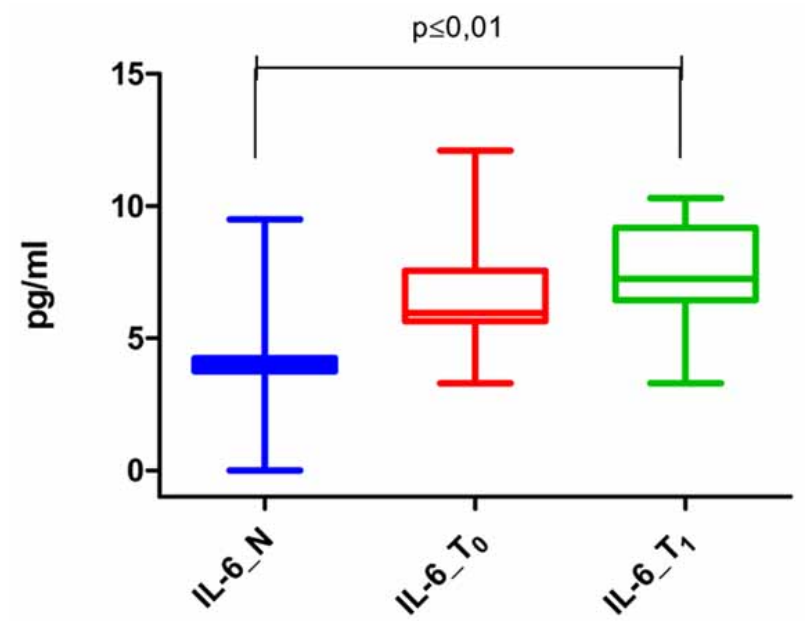

Fig. (4). Serum levels of IL-6 before $\left(T_{0}\right)$ and after $\left(T_{1}\right)$ synbiotic administration. The cytometric bead array (CBA) test was used for cytokine determination. $\mathrm{N}=10$ normal donors.

\section{DISCUSSION}

Ageing is characterized by a severe imbalance between cell maintenance and repair systems which ultimately leads to a depressed response toward external and internal stimuli [26,27]. In particular, impairment of the immune response in elderly, the socalled immunosenescence, accounts for the high frequency of infections and inflammatory events with ageing [28]. In this framework, our data clearly demonstrate an impaired immunity in the group of free-living elderly enrolled for this study.

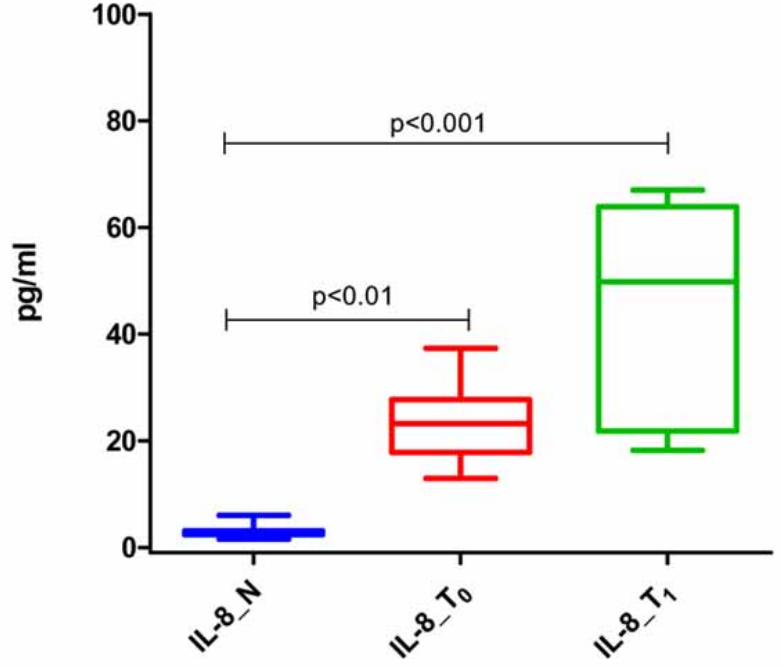

Fig. (5). Serum levels of IL-8 before $\left(T_{0}\right)$ and after $\left(T_{1}\right)$ synbiotic administration. The cytometric bead array (CBA) test was used for cytokine determination. $\mathrm{N}=10$ normal donors.

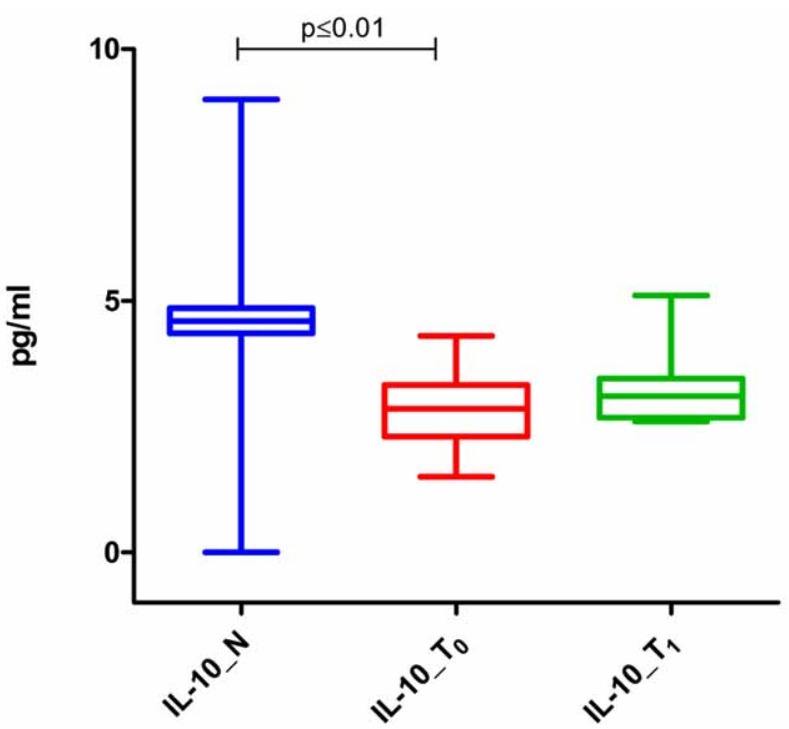

Fig. (6). Serum levels of IL-10 before $\left(T_{0}\right)$ and after $\left(T_{1}\right)$ synbiotic administration. The cytometric bead array (CBA) test was used for cytokine determination. $\mathrm{N}=10$ normal donors.

In our subjects, the reduced levels of serum IL-12 indicate the incapability of the aged host to skew the adaptive immune response toward the $\mathrm{Th}_{1}$ pathway. Similar results have been published by Stout-Delgado and associates [29] who observed an impairment of plasmacytoid DCs with reduced release of interferon- $\alpha$ and IL-12 in response to bacterial stimuli. This fact may contribute to the increased frequency of infections reported in aged humans. However, also the bone marrow lymphopoiesis is impaired in aging with a profound decline of B cell development, which seems to be sex steroid dependent [30]. Therefore, this immune defect may account for recurrent infections in elderly, too.

Quite interestingly, the reduced activation of the TH1 pathway by IL-12 is complicated by a profound immune dysfunction of the aged $\mathrm{T}$ cell compartment [31]. In fact, thymus atrophy and reduction of naïve $\mathrm{T}$ cells lead to a dramatic shrinkage of the $\mathrm{T}$ cell repertoire being responses directed against ubiquitary infectious 
pathogens [31]. This fact indicates the complexity of immune disorders in aging.

In the present study proinflammatory cytokines, such as TNF- $\alpha$ and, mostly, IL-1 $\beta$ are detectable in minute amounts, thus indicating a deficit of innate immunity, as reported by others [32]. In addition another study reported the negative effects of aging on in vitro Toll-Like Receptor-mediated proinflammatory responses in macrophages [33]. The consequential lack of proinflammatory cytokine secretion seems to further aggravate the age related decline in $\mathrm{T}$ cell function and this has been overcome by the use of proinflammatory adjuvants in mice [34].

On the other hand, the IL-10 mediated antinflammatory response is also reduced in our aged group in comparison with the young counterpart. In this framework, according to Henson and associates [35] inhibitory molecules, such as CTLA-4 and PD-1, can deliver negative signals able to alter the balance between $\mathrm{T}$ cell activation and tolerance.

Strikingly, the acute phase response is more preserved in these aged subjects either in terms of IL- 6 or of IL- 8 amounts. Especially IL-8 values are higher than the younger counter part and neutrophil chomotaxis may afford protection to the host in the acute phase of inflammatory processes.

Quite interestingly, synbiotic administration leads to an increase of IL-1 $\beta$ and IL-6 in a significant manner. However, the best result is evident in the case of $\mathrm{IL}-8$, whose levels continue to increase despite higher baseline values than controls.

On the other hand, in the case of IL-12, TNF- $\alpha$ and IL-10 a slight trend to increase was observed at $T_{1}$. Previous reports have pointed out the ability of $L$. casei to favor the Th1-type response via release of IL-12 by macrophages [36]. In our case, the trend to increase in IL-10, even if modest, in concomitance with that of IL12 may maintain the IL-10: IL-12 ratio in equilibrium, thus eliciting protective effects as observed in a murine model of experimental colitis [37-39]. This probiotic-dependent effect seems to be mediated via inhibition of the NF-KB pathway, thus leading to suppression of inflammatory response [40]. In this regard, in a recent report Schiffrin and associates [41] have demonstrated that probiotic administration in healthy elderly could normalize the response to endotoxins reducing low-grade inflammation.

In the light of the results obtained through this pilot study, increase in dosage and prolongation of synbiotic administration are required in order to attain better results mostly in terms of adaptive response improvement. At the same time, a melioration of clinical manifestations (e.g., reduction of winter infections) should be followed-up in elderly in order to support the laboratory findings [42].

Finally, in this context other immune therapies under study should be mentioned for age-related diseases, such as vaccination against shingles, Alzheimer's disease and atherosclerosis [43]. Furthermore, due to the complexity of processes leading to immunosenescence [44-46] a series of vaccines against bacterial and viral infectious diseases has recently been developed [47]. Since vaccination in aging is not very efficacious because of the impaired immune response, all therapeutical measures aimed at modulating the immune balance, even including administration of synbiotics, should be pursued.

In conclusion, in vitro investigations as well as clinical trials in free-living elderly are important for a better understanding of those mechanisms responsible for immunosenescence.

\section{ACKNOWLEDGMENT}

Paper supported by Ministry of Health, Rome (Italy)

\section{ABBREVIATIONS}

APC $=\quad$ Antigen Presenting Cells

$\begin{array}{lll}\mathrm{CBA} & = & \text { Cytometric Bead Array } \\ \mathrm{DC} & = & \text { Dendritic Cells } \\ \mathrm{IFN} & = & \text { Interferon } \\ \mathrm{IL} & = & \text { Interleukin } \\ \mathrm{LGG} & = & \text { Lactobacillus rhamnosus } \text { Gorbach and Goldin } \\ \mathrm{M} \varnothing & = & \text { Macrophages } \\ \mathrm{PP} & = & \text { Peyer's patches }\end{array}$

\section{REFERENCES}

[1] Parvez S, Malik KA, Ah Kang S, Kim HY. Probiotics and their fermented foods products are beneficial for health. J Appl Microbiol 2006; 100: 1171-85.

[2] Hattaka K, Savilahti E, Pönkä A, Meurman JH, Poussa T, Näse L, et al. Effect of long term consumption of probiotic milk on infections in children attending day care centers: double blind randomized trial. BMJ 2001; 322: 1327.

[3] Canani RB, Cirillo P, Terrin G, Cesarano L, Spagnuolo MI, De Vincenzo A, et al. Probiotics for treatment of acute diarrhea in children: randomized clinical trial of five different preparations. BMJ 2007; 335: 340-5.

[4] Delia P, Cirillo P, Terrin G, Cesarano L, Spagnuolo MI, De Vincenzo A, et al. Use of probiotics for prevention of radiationinduced diarrhea. World J Gastroenterol 2007; 13: 912-5.

[5] Rembacken BJ, Snelling AM, Hawkey PM, Chalmers DM, Axon AT. Non pathogenic Escherichia coli versus mesalazine for the treatment of ulcerative colitis: a randomized trial. Lancet 1999; 354: 635-9.

[6] Zocco MA, dal Verme LZ, Cremonini F, Piscaglia AC, Nista EC, Candelli M, et al. Efficacy of Lactobacillus GG in maintaining remission of ulcerative colitis. Aliment Pharmacol Ther 2006; 23: 1567-74.

[7] Ishikawa H, Akedo I, Umesaki Y, Tanaka R, Imaoka A, Otani T. Randomized controlled trial of the effect of bifidobacteriafermented milk on ulcerative colitis. J Am Col Nutr 2003; 22: 5663.

[8] Gionchetti P, Rizzello F, Venturi A, Brigidi P, Matteuzzi D, Bazzocchi G, et al. Oral bacteriotherapy as maintenance treatment in patients with chronic pouchitis: a double blind, placebo-control trial. Gastroenterology 2000; 119: 305-9.

[9] Kalliomaki M, Salminen S, Arvilommi H, Kero P, Koskinen P, Isolauri E. Probiotics in primary prevention of atopic diseases: a randomized placebo-controlled trial. Lancet 2001; 357: 1076-9.

[10] Weston S, Halbert A, Richmond P, Prescott SL. Effects of probiotics on atopic dermatitis: a randomized controlled trial. Arch Dis Child 2005; 90: 892-7.

[11] Xiao JZ, Kondo S, Yanagisawa N, Takahashi N, Odamaki T, Iwabuchi $\mathrm{N}$, et al. Effect of probiotic Bifidobacterium longum BB536 in relieving clinical symptoms and modulating plasma cytokine levels of Japanese cedar pollinosis during the pollen season. A randomized double-blind, placebo-controlled trial. J Investig Allergol Clin Immunol 2006; 16: 86-93.

[12] Tamura M, Shikina T, Morihana T, Hayama M, Kajimoto O, Sakamoto A, et al. Effects of probiotics on allergic rhinitis induced by Japanese cedar pollen: randomized double blind, placebo controlled clinical trial. Int Arch Allergy Immunol 2007; 143: 7582.

[13] Giovannini M, Agostoni C, Riva E, Salvini F, Ruscitto A, Zuccotti GV, et al. Felicita Study Group. A randomized prospective double blind controlled trial on effects of long-term consumption of fermented milk containing Lactobacillus casei in pre-school children with allergic asthma and/or rhinitis. Pediatr Res 2007; 62: 215-20.

[14] Caruso C, Jirillo E. Drug targets in ageing and age-associated diseases. Curr Pharm Des 2008; 14: 2635-6.

[15] Turchet P, Laurenzano M, Auboiron S, Antoine JM. Effect of fermented milk containing the probiotic Lactobacillus casei DN114001 on winter infections in free-living elderly subjects: a randomized controlled pilot study. J Nutr Health Aging 2003; 7: 757.

[16] Fukushima Y, Miyaguchi S, Yamano T, Kaburagi T, Iino H, Ushida $\mathrm{K}$, et al. Improvement of nutritional status and incidence of infection in hospitalized enterally fed elderly by feeding of 
fermented milk containing probiotic Lactobacillus Johnsonii La1 (NCC533). Br J Nutr 2007; 98: 969-77.

[17] Shida K, Nanno M. Probiotics and immunology: separating the wheat from the chaff. Trends Immunol 2008; 29: 565-73.

[18] Niers LE, Hoekstra MO, Timmerman HM, van Uden NO, de Graaf $\mathrm{PM}$, Smits $\mathrm{HH}$, et al. Selection of probiotics bacteria for prevention of allergic disease: immunomodulation of neonatal dendritic cells. Clin Exp Immunol 2007; 149: 344-52.

[19] Smits HH, Engering A, van der Kleij D, de Jong EC, Schipper K, van Capel TM, et al. Selective probiotic bacteria induce IL-10producing regulatory $\mathrm{T}$ cells in vitro by modulating dendritic cell function throught dendritic cell-specific intercellular adhesion molecule 3- grabbing non integrin. J Allergy Clin Immunol 2005; 115: $1250-7$

[20] Denning TL, Wang YC, Patel SR, Williams IR, Pulendran B. Lamina propria macrophages and dendritic cells differentially induce regulatory and interleukin 17 -producing $\mathrm{T}$ cell responses. Nat Immunol 2007; 8: 1086-94.

[21] Robertson MD, Bikerton A, Dennis AL, Vidal H, Frayn KH. Insuline-sensitizing effects of dietary resistant starch and effects on skeletal muscle and adipose tissue metabolism. Am J Clin Nutr 2005; 82: 559-67.

[22] Eckburg PB, Bik EM, Bernstein CN, Purdom E, Dethlefsen L, Sargent M, et al. Diversity of human intestinal microbial flora. Science 2005; 308: 1635-8.

[23] Kanamori Y, Sugiyama M, Hashizume K, Yuki N, Morotomi M, Tanaka R. Experience of long term synbiotic therapy in seven short bowel patients with refractory enterocolitis. J Gastroenterol 2007; 13: $236-43$.

[24] Guigoz Y, Rochat F, Pervisseau-Carrier G. Effects of oligosaccharide on the fecal flora and non- specific immune system in elderly people. Nutr Res 2002; 26: 372-6.

[25] Bunout D, Hirsch S, Pía de la Maza M, Muñoz C, Haschke F, Steenhout $\mathrm{P}$, et al. Effects of prebiotics on the immune response to vaccination in the elderly. JPEN 2002; 26: 372-6.

[26] Dicarlo AL, Fuldner R, Kaminski J, Hodes R. Aging in the context of immunological architecture, function and disease outcomes. Trends Immunol 2009; 30: 293-4.

[27] Dowling MR, Hodgkin PD. Why does the thymus involute? A selection-based hypothesis. Trends Immunol 2009; 30: 295-300.

[28] Jirillo E, Candore G, Magrone T, Caruso C. A scientific approach to anti-ageing therapies: State of the art. Curr Pharm Des 2008; 14: 2637-42.

[29] Stout-Delgado HW, Yang X, Walker WE, Tesar BM, Goldstein DR. Aging impairs IFN regulatory factor 7 up-regulation in plasmacytoid dendritic cells during TLR9 activation. J Immunol 2008; 181: 6747-56.

[30] Dudakov JA, Goldberg GL, Reiseger JJ, Chidgey AP, Boyd RL. Withdrawal of sex steroids reverses age- and chemotherapy-related defects in bone marrow lymphopoiesis. J Immunol 2009; 182: 6247-60

[31] Maue AC, Yager EJ, Swain SL, Woodland DL, Blackman MA, Haynes L. T-cell immunosenescence: lessons learned from mouse models of aging. Trends Immunol 2009; 30: 301-5.
[32] Kovacs EJ, Palmer JL, Fortin CF, Fülöp T, Jr, Goldstein DR, Linton PJ. Aging and innate immunity in the mouse: impact of intrinsic and extrinsic factors. Trends Immunol 2009; 30: 319-24.

[33] Boehmer ED, Meehan MJ, Cutro BT, Kovacs EJ. Aging negatively skews macrophage TLR2- and TLR4-mediated pro-inflammatory responses without affecting the IL-2-stimulated pathway. Mech Ageing Dev 2005; 126: 1305-13.

[34] Maue AC, Eaton SM, Lanthier PA, Sweet KB, Blumerman SL, Haynes L. Proinflammatory adjuvants enhance the cognate helper activity of aged CD4 T cells. J Immunol 2009; 182: 6129-35.

[35] Henson SM, Macaulay R, Kiani-Alikhan S, Akbar AN. The use of the inhibitory receptors for modulating the immune responses. Curr Pharm Des 2008; 14: 2643-50.

[36] Shida K, Makino K, Morishita A, Takamizawa K, Hachimura S, Ametani A, et al. Lactobacillus casei inhibits antigen-induced IgE secretion through regulation of cytokine production in murine splenocyte cultures. Int Arch Allergy Immunol 1998; 115: 278-87.

[37] Matsumoto S, Hara $T$, Hori $T$, Mitsuyama K, Nagaoka M, Tomiyasu N, et al. Probiotic lactobacillus-induced improvement in murine chronic inflammatory bowel disease is associated with the down-regulation of pro inflammatory cytokines in lamina propria mononuclear cells. Clin Exp Immunol 2005; 140: 417-26.

[38] Borruel N, Carol M, Casellas F, Antolín M, de Lara F, Espín E, et al. Increased mucosal tumour necrosis factor $\alpha$ production in Crohn's disease can be downregulated ex vivo by probiotic bacteria. Gut 2000; 51: 659-64.

[39] Zhang L, Li N, Caicedo R, Neu J. Alive and dead Lactobacillus rhamnosus GG decrease tumor necrosis factor- $\alpha$ - induced IL-8 production in Caco-2 cells. J Nutr 2005; 135: 1752-6.

[40] Jijon H, Backer J, Diaz H, Yeung H, Thiel D, McKaigney C, et al. DNA from probiotic bacteria modulates murine and human epithelial and immune function. Gastroenterology 2004; 126: 135873.

[41] Schiffrin EJ, Parlesak A, Bode C, Bode JC, van't Hof MA, Grathwohl D, et al. Probiotic yogurt in the elderly with intestinal bacterial overgrowth: endotoxaemia and innate immune functions. Br J Nutr 2009; 101: 961-6.

[42] Hamilton-Miller JM. Probiotics and prebiotics in the elderly. Postgrad Med J 2004; 80: 447-51.

[43] Weksler ME, Pawelec G, Franceschi C. Immune therapy for agerelated diseases. Trends Immunol 2009; 30: 344-50.

[44] Lynch HE, Goldberg GL, Chidgey A, Van den Brink MR, Boyd R, Sempowski GD. Thymic involution and immune reconstitution. Trends Immunol 2009; 30: 366-73.

[45] Cancro MP, Hao Y, Scholz JL, Riley RL, Frasca D, Dunn-Walters DK, et al. B cells and aging: molecules and mechanisms. Trends Immunol 2009; 30: 313-8.

[46] Panda A, Arjona A, Sapey E, Bai F, Fikrig E, Montgomery RR, et al. Human innate immunosenescence: causes and consequences for immunity in old age. Trends Immunol 2009; 30: 325-33.

[47] Chen WH, Kozlovsky BF, Effros RB, Grubeck-Loebenstein B, Edelman R, Sztein MB. Vaccination in the elderly: an immunological perspective. Trends Immunol 2009; 30: 351-9. 